Revista de Filosofía

Volumen 71 (2015) 177-190

\title{
CONSIDERACIONES BIOÉTICAS Y BIOPOLÍTICAS ACERCA DEL TRANSHUMANISMO. EL DEBATE EN TORNO A UNA POSIBLE EXPERIENCIA POSTHUMANA
}

\author{
Raúl Villarroel \\ Universidad de Chile \\ rvillarr@uchile.cl
}

Resumen / Abstract

\begin{abstract}
Considerando que el transhumanismo es una particular deriva de la reflexión contemporánea, que sostiene la idea de que el actual estado de la humanidad no es el definitivo sino uno simplemente transitorio, que puede y debe ser intervenido tecnocientíficamente en procura de su mejoramiento, en este artículo se examinan las implicancias bioéticas y biopolíticas de tal presupuesto. Se atiende para ello a las complejas y dilemáticas circunstancias derivadas de la perspectiva transhumana, que están vinculadas con la probable trasgresión de los derechos de las personas presentes o futuras y el eventual control absoluto de la vida como el que algunos de sus detractores afirman que inevitablemente se generaría a partir de semejante tipo de intervenciones biotecnológicas. Se intentará indagar críticamente en el ideario del transhumanismo tomando como referencia para el análisis la articulación indisoluble que en la modernidad se ha establecido entre el desarrollo de las tecnologías y aquella racionalidad política que sustenta las estrategias de la gubernamentalidad neoliberal. Se espera plantear con ello una inquietud y un conjunto de interrogantes respecto de los riesgos asociados a los modos hasta hora insospechados de producción, administración y control biopolítico de la subjetividad que podrían estar ligados inadvertidamente a la idea transhumanista.
\end{abstract}

Palabras Clave: transhumanismo, bioconservacionismo, posthumanismo, biopolítica, bioética.

\section{BIOETHICAL AND BIOPOLITICAL REMARKS ON TRANSHUMANISM. ARGUING ABOUT THE POSTHUMAN CONDITION}

Understanding Transhumanism as a particular turn of contemporary reflection that maintains the current state of humanity is not the final but just a transitional one, which can and should be scientific and technologically enhanced, the bioethical and biopolitical implications of such situation will be examined in this paper. Here it will be explored the transhumanist ideas related to the indissoluble link that in modern times have been established between the development of technologies and politics and strategies of neoliberal governmentality. This is expected to pose a set of questions about the risks associated to the unsuspected modes of production, management and biopolitical control of subjectivity that may be allegedly linked to the transhumanist idea.

KEY WORDS: transhumanism, bioconservationism, posthumanism, biopolitics, bioethics. 


\section{Introducción}

R⿴囗十

Probablemente, las tajantes consideraciones que Jürgen Habermas planteó en

"El futuro de la naturaleza humana" (Habermas 2001) constituyan la evidencia filosófica hasta ahora más conocida y comentada respecto de las complejidades de diverso orden que trae consigo el proyecto ya desplegado de intervención de la vida humana. Mucho más allá de ancestrales sueños y pesadillas que han acompañado a la humanidad en su desarrollo, hoy nos corresponde atestiguar la viabilidad de inéditos y, al mismo tiempo, extraordinarios "productos" de las biotecnologías y la manipulación genética. Ante tal novedoso horizonte problemático es que el pensador alemán manifiesta su inquietud respecto del tránsito que se estaría produciendo desde una eugenesia simplemente negativa, como aquella que se ha propuesto por fin evitar el desarrollo de ciertas enfermedades de tipo hereditario -con el propósito de no transmitirlas a las generaciones sucesivas-, hacia una eugenesia liberal, comprometida interesadamente con los imperativos del mercado y que ya no orienta su quehacer hacia una dimensión puramente terapéutica, dirigiéndose, en cambio, hacia intervenciones perfeccionistas de lo humano.

Se podría decir que este prurito habermasiano no hace sino aludir a una discusión que, si bien es cierto no es reciente, de todos modos ha surgido como interés teórico relevante solo durante lo que va del presente siglo, acaparando la atención de muchos científicos, filósofos, juristas, bioeticistas y políticos, preocupados también por el futuro de la naturaleza humana. Asimismo, el tema se constituye cada vez más en objeto de la ocupación preferente de variadas organizaciones de la sociedad civil: ambientalistas, animalistas, grupos religiosos, asociaciones académicas, entre otras. En torno de esta masa crítica, interpelada por la decisiva importancia que tiene el futuro de la naturaleza humana, se ha instalado una inédita plataforma de observación de nuestra propia especie.

Se trata del controvertido tema del "transhumanismo", una denominación que Peter Sloterdijk, en su conferencia Reglas para el Parque humano, de 1999, había ocupado -aunque sin especificar mayormente, al menos en los términos en que a partir de ahora aquí lo haremos- para calificar a la crítica que en su Carta sobre el humanismo, de 1946, Heidegger dirigiera al joven pensador francés Jean Beaufret. Sloterdijk definió la conocida Carta como la inauguración de un "espacio de pensamiento transhumanista o posthumanista" (Sloterdijk 1999) porque no representaba otra cosa sino una suerte de condena del humanismo, debido a que Heidegger se preguntaba si acaso en la "catástrofe presente se mostraba precisamente, que el problema es el hombre mismo junto con sus sistemas de autoelucidación y autoensalzamiento metafísico"; revelándose de paso con ello que cuando se desarrollan positivamente los poderes científicos, no sería sino una triste figura de los seres humanos la que, como en épocas de temprana inocencia, quisiera colocar una fuerza superior en su lugar (Dios, la casualidad o los otros). En el futuro -afirmará casi optimistamente Sloterdijk- este juego se encarará activamente y se formulará un código de las antropotécnicas, que cambiará el significado del humanismo clásico puesto que "la humanitas no solo implica la amistad del hombre con el hombre, sino también -y de modo crecientemente explícito-que el ser humano representa el más alto poder para el ser humano" (Sloterdijk 1999). Por cierto, aunque esta definición en 
principio escapa de lo que a continuación trataremos de explicitar acá, la mantendremos por ahora en reserva para aludir indirectamente a ella más adelante, en provecho de la reflexión de fondo que pretendemos desarrollar en estas líneas.

\section{Transhumanismo}

Hay quienes piensan que el verdadero origen del concepto transhumanismo se encontraría en un texto de 1957 del biólogo humanista Julian Huxley -hermano del famoso escritor Aldous Huxley, y nieto del no menos célebre biólogo Thomas H. Huxley- titulado New bottles for a new wine, donde habría propuesto el término "transhumanismo" para impulsar la idea según la cual el ser humano debe mejorarse a sí mismo, a través de la ciencia y la tecnología, ya sea desde el punto de vista genético o desde el punto de vista ambiental y social. Tomándonos entonces de este antecedente, y sintetizando lo expuesto en las miles de páginas que hasta la fecha se han escrito sobre este tema, se podría definir al transhumanismo como la posición de quienes creen que es posible provocar deliberadamente un "mejoramiento" (enhancement) de los seres humanos, con miras a alcanzar un estado superior, a veces llamado "transhumano", o incluso "posthumano".

En nuestros días, uno de los más afamados pensadores transhumanistas, el filósofo australiano Julian Savulescu, director del reconocido Centro Uehiro de Ética Práctica de la Facultad de Filosofía de la Universidad de Oxford, precisa que tales mejoras "incluyen una familia de diferentes clases, tales como el tratamiento médico de las enfermedades, el incremento del potencial humano natural, por ejemplo, el incremento de la dotación natural de capacidades de una persona dentro del rango típico de la especie Homo sapiens, tales como elevar el CI de una persona de 100 a 140; y las mejoras suprahumanas (a veces llamadas posthumanas o transhumanas), es decir, el incremento de las capacidades de una persona más allá del rango típico de la especie, por ejemplo, proporcionar un sonar o un CI por encima de 200" (Savulescu 2012, p. 267).

De tal manera, el transhumanismo afirmaría que es necesario, $\mathrm{y}$-aun más-que es deseable, mejorar la condición humana; aunque con ello, en verdad, no refieren a mejoras conseguidas únicamente a través del sistema educacional o a aquellas modificaciones socioambientales determinadas, por ejemplo, por la economía o la cultura, sino a aquellas otras que recurriendo a medios técnicos intervienen directamente el organismo humano para lograrlo, es decir, interviniendo directamente su sustrato fisiológico-corporal. Los transhumanistas piensan que existen importantes motivaciones para sostener que las capacidades humanas actuales pueden ser ampliadas mediante dispositivos técnicos y que, incluso, hasta el comportamiento ético podría ser igualmente objeto de modificaciones o mejoras por vía de procedimientos de ingeniería genética (Garrido 2007).

Los transhumanistas ven la naturaleza humana, entonces, como una obra en desarrollo, un trabajo en progreso, que nos desafiaría a intentar su rediseño, conforme a una serie de antiguas aspiraciones de los seres humanos, que han estado presentes desde 
tiempos inmemoriales. Sería cosa de pensar, nada más y por ejemplo, en la búsqueda de la inmortalidad presente en el poema sumerio de Gilgamesh (ca. 1700 a.n.e.), o en el ejemplo paradigmático del deseo de volar que mueve a Ícaro y Dédalo, o en la idea medieval de creación del homúnculo, por citar nada más unos cuantos casos conocidos de pretensiones históricas de ampliación de las potencias de la humanidad (Bostrom 2005a). Nuestra actual condición, entonces, no debería considerarse forzosamente como el punto de arribo de la evolución, sino únicamente como una fase inicial suya, tras la cual debiesen venir tales mejoramientos, propiciados por el incremental saber de la ciencia y la técnica.

\section{Los autores}

Esto es, ciertamente, lo que afirma el filósofo oxoniense Nick Bostrom, otro destacado representante de esta corriente de pensamiento, director del Future of Humanity Institute y fundador de la Asociación Transhumanista Mundial, quien señala que el transhumanismo es un movimiento hasta ahora poco definido, que se ha desarrollado gradualmente durante las dos últimas décadas, y que puede ser visto como una consecuencia del humanismo secular y de la Ilustración. Bostrom sostiene que la naturaleza humana actual es mejorable a través del uso de la ciencia aplicada y de otros métodos racionales, lo que puede permitir aumentar, por ejemplo, la duración de la salud humana, o extender nuestras capacidades intelectuales y físicas, y darnos un mayor control sobre nuestros propios estados mentales y del ánimo (Bostrom 2005b, p. 202).

En tal sentido, se podría constatar que algunas de las posibilidades de mejoramiento promovidas por los transhumanistas son ya una realidad entre nosotros; por ejemplo, todos los más recientes desarrollos en psicofarmacología, o la variada gama de medicamentos que aumentan el rendimiento físico de los deportistas; o los avances cada vez más sorprendentes en tecnologías de la información y en técnicas de ingeniería genética, actualmente en fase de desarrollo experimental. También se podrían considerar como ilustración de tal situación, por ejemplo, las incipientes aplicaciones de la biónica (artefactos mecánicos que se integran en el cuerpo humano; sin ir más lejos, piénsese en el caso tan mediático del atleta Oscar Pistorius), la curación de enfermedades desde el interior del propio cuerpo mediante el empleo de nanorobots y algunas otras experimentaciones semejantes actualmente en curso, como las referidas a procesos de suspensión vital como el de la crionización; o bien, los experimentos de realidad virtual enteramente inmersiva, así como muchas otras expresiones de desarrollos tecnocientíficos semejantes a estos. En suma, lo que los transhumanistas defienden es la posibilidad de que se aliente una proliferación del conjunto de técnicas que satisfacen nuestra demanda de mejoramiento, no conformándose con las posibilidades actuales, sino planteando otras, mucho más ambiciosas en cuanto a sus expectativas e ilimitada performatividad.

Los transhumanistas sostienen la idea de que estas tecnologías de mejoramiento humano deben estar disponibles, y que los individuos deben tener una amplia 
discrecionalidad para determinar cuáles de ellas aplicar a sí mismos (que es a lo que llaman "la libertad morfológica") y, además, que los padres deben llegar a decidir normalmente qué tecnologías reproductivas usar cuando lleguen a tener hijos (lo que denominan "la libertad reproductiva") (Ibíd., p. 202). En este último sentido, son bien conocidas las ideas de Savulescu, quien sostiene que "tenemos una obligación moral de realizar pruebas para detectar la contribución genética en estados no patológicos y de utilizar la información resultante en nuestras decisiones reproductivas" (Savulescu 2012, p. 44). A esto, Savulescu lo denomina "beneficencia procreativa" y la concibe como el requerimiento moral que interpela a quien en ausencia de alguna otra razón busca justificar su aspiración de tener la mejor descendencia posible.

No obstante, ante todo ello parece necesario tener presente que tal posibilidad se aparta sustancialmente de la imagen de ser humano que la tradición clásica y la modernidad se esforzaron por estatuir. En este sentido, ciertas cualidades naturales, $\mathrm{u}$ ontológicas -como las denominó la filosofía-, tales como la inteligencia o la belleza por ejemplo, que hoy se advierten como susceptibles de ser producidas conforme a la voluntad del individuo y merced a los dispositivos tecnológicos disponibles, siempre excedieron por completo a nuestras capacidades en relación con su distribución o establecimiento individual, dado que su asignación personalizada le correspondía a la Providencia Divina o a la evolución por selección natural. Del mismo modo, la propagación por vía del desarrollo sexual de nuestra especie, determinada por la Providencia, según algunos, y por la selección natural, según otros, ahora podría verse, en muy corto tiempo, establecida por los mismos dispositivos científicotécnicos que comienzan a intervenir la vida humana en nuestra época.

Los transhumanistas argumentan que, si bien es cierto se puede pensar en determinados peligros o amenazas, cuya virtualidad debería ser claramente identificada -o anticipada y evitada su hipotética ocurrencia-, las capacidades científicas y los recursos tecnológicos que apuntan a producir mejoramiento humano de todos modos nos ofrecerían un potencial más que significativo para empleos altamente valiosos y que, a la vez, pueden ser considerados sin vacilación alguna como humanamente beneficiosos. Ellos parecen confiar en que dichos mejoramientos tendrían la facultad para hacer de nosotros, o de quienes nos vayan a suceder habitando este planeta, individuos "posthumanos". Con esto se refieren a individuos que -por citar un par de características- tendrían una salud mucho más resistente, lo que les procuraría una longevidad hasta ahora desconocida en la especie humana. Así como también facultades cognitivas insospechadamente superiores a las de los actuales hombres y mujeres de este mundo. Es decir, adquirirían un nuevo estatuto ontológico, determinado por nuevos modos de ser, por otra forma de sentir y vivir la vida. Y, sumado a ello, una gran capacidad para emplear de múltiples formas -desconocidas hasta hoy- dichas facultades, en los nuevos escenarios de la existencia futura.

Por tanto, teniendo a la vista esta perspectiva -argumentan los transhumanistassería prudente abrazar decididamente el avance y el desarrollo tecnológico; aunque, a la vez -y dicen estar muy conscientes de ello- habría que adoptar medidas específicas contra amenazas concretas que pudieran estar asociadas a tales innovaciones, como el abuso militar o terrorista de las armas biológicas, por ejemplo; o los indeseados efectos 
colaterales medioambientales y sociales de las intervenciones tecnológicas operadas sobre la vida humana. En relación con esto último, me permitiría plantear una inquietud de manera solo marginal, que no desarrollaré in extenso en estas páginas porque creo que amerita su propio tratamiento específico en reflexiones posteriores. Me refiero al hecho de que, según mi parecer, y hasta dónde puedo dar cuenta con mi indagación, no parece que se haya propuesto ningún gran desarrollo o preocupación teórica respecto del asunto de la sustentabilidad ambiental futura por parte de los pensadores transhumanistas; lo que podría considerarse al menos curioso, dada la relevancia y el carácter estratégico que esta situación tiene para la continuidad de la vida humana sobre el planeta. Sin lugar a dudas, las implicancias medioambientales de la existencia de individuos o sociedades posthumanas, de sujetos ampliamente mejorados en sus capacidades, que habitarán el planeta de otro modo, desplegando un repertorio de conductas cuyo impacto ecológico es todavía muy impredecible, es una cuestión que parece digna de ser tenida en cuenta en cualquier planificación futura de la sociedad humana.

\section{El bioconservacionismo}

En oposición a esta perspectiva transhumanista, se ha levantado un planteamiento crítico así llamado "bioconservador", que argumenta contra el uso de las tecnologías para modificación de la naturaleza humana. Entre los más prominentes bioconservacionistas se incluyen autores como Leon Kass, Francis Fukuyama o George Annas, o incluso el propio Jürgen Habermas. Una de las preocupaciones centrales de los bioconservadores es que las tecnologías de mejoramiento humano pueden llegar a "deshumanizar" (Bostrom 2005 b, p. 203). Esta preocupación, que ha sido ampliamente sostenida, afirma que estas tecnologías pueden socavar nuestra dignidad humana o inadvertidamente erosionar aquello que es profundamente valioso en el ser humano y que es difícil expresar con palabras o en términos de un simple análisis de costo-beneficio. Un autor como Francis Fukuyama, por ejemplo, plantea en relación con esto: "que hay algo único en la raza humana, que provee a cada miembro de la especie con un estatuto moral superior al del resto del mundo natural" (Fukuyama 2002, p. 149). En algunos casos, tal prurito parece derivar de sentimientos religiosos, mientras que en otros derivaría de motivos puramente seculares.

La mejor estrategia, por tanto -argumentan los bioconservadores-, es implementar limitaciones globales a la promesa de expansión de las tecnologías de mejoramiento humano, para evitar ingresar en una "pendiente resbaladiza", que conduzca a un estado posthumano definitivamente degradado, lo que conduciría, en verdad, a muy verosímiles resultados de "infrahumanidad". O bien, porque ese ser pretendidamente "posthumano" podría llegar a constituir una amenaza para los actuales seres humanos normales, puesto que podría llegar a querer establecer un dominio y una supremacía absolutamente injustas sobre ellos, merced a unas capacidades mejoradas de las que usufructuaría y que no serían distribuidas equitativamente entre toda la población del 
planeta, lo que lo facultaría para el dominio de aquellos otros individuos humanos remanentes en cuanto a su potencialidad.

Esto último es lo que inquieta a bioeticistas como George J. Annas, cuando sostiene: "La nueva especie, o el 'posthumano', probablemente verá a los viejos humanos "normales" como inferiores, incluso salvajes, y los conducirá a la esclavitud o a la matanza. Los normales, por su parte, pueden ver a los posthumanos como una amenaza $\mathrm{y}$, si pueden, se meterán en un ataque preventivo asesinando a los posthumanos antes de que ellos mismos sean asesinados o hechos esclavos. Es finalmente este predecible potencial de genocidio lo que hace de los experimentos de alteración de la especie potenciales armas de destrucción masiva, y hace del irresponsable ingeniero genético un potencial bioterrorista" (Annas 2002).

Intentando resguardar una suerte de naturaleza humana específica, Leon Kass, el bioeticista conservador estadounidense, sostiene: "La mayor parte de los dones de la naturaleza les han sido dados a especies particulares: todas y cada una son de una clase determinada. Las cucarachas y los seres humanos están igualmente dotados pero naturalmente diferenciados. Convertir a un hombre en cucaracha-como no necesitamos que Kafka nos lo demuestre- sería deshumanizarlo. Tratar de convertir a un hombre en algo más que un hombre podría estar bien. Pero, necesitamos algo más que apreciaciones generales respecto de los dones naturales. Necesitamos una mirada particular y respeto por ese don especial que es la naturaleza que se nos ha dado" (Kass 2003).

Por su parte, Fukuyama, en un tono derechamente precautorio, señala: “Al fin y al cabo, la raza humana es un poco desastrosa, con nuestras tercas enfermedades, nuestras limitaciones físicas y la brevedad de nuestra vida. Si a ello añadimos las envidias, la violencia y las angustias, el proyecto transhumanista empieza a parecer razonable. Si fuera tecnológicamente posible, ¿por qué no íbamos a querer superar nuestra especie actual? La aparente sensatez del plan, sobre todo si se proyecta hacer de forma gradual, es una de las cosas que lo hace peligroso. La sociedad no va a caer de repente bajo el hechizo de la concepción transhumanista. Pero es muy posible que mordisqueemos las tentadoras ofertas de la biotecnología sin darnos cuenta de su aterrador coste moral" (Fukuyama 2004).

Sintéticamente expuesto, podría decirse que los pensadores que adhieren a una posición bioconservacionista sintonizan al menos con dos ideas fundamentales que en la reflexión ética referida al devenir técnico, social y cultural de Occidente prosperaron a partir de fines de siglo XX. Estas son las de "riesgo" y de "responsabilidad"; que, como sabemos, fueron defendidas con mayor propiedad por autores como los alemanes Ulrich Beck y Hans Jonas, respectivamente. Beck, por ejemplo, había señalado: "Si antes existían peligros generados externamente (dioses, naturaleza), el nuevo carácter - desde el punto de vista histórico- de los actuales riesgos radica en su simultánea construcción científica y social" (Beck 1998, p. 203.); mientras que por su parte, años antes, Jonas había afirmado: "la promesa de la técnica moderna se ha convertido en una amenaza, o que la amenaza ha quedado indisolublemente asociada a la promesa" (Jonas 1995, p. 15), por lo cual "ese mismo deber recién aparecido [...] se resume en el concepto de responsabilidad" (Ibíd., p. 16). 


\section{Nietzsche y el transhumanismo}

El debate entre transhumanismo y bioconservacionismo no se agota o restringe únicamente a una toma de posición respecto del uso y la aplicación de dispositivos biotecnológicos. Tras de ello, también se busca responder a una pregunta que la filosofía, desde hace mucho, había hecho suya: la pregunta por el hombre, su naturaleza y sus posibles transformaciones. Esta misma preocupación es la que ha dado lugar a importantes divergencias en relación con el debate transhumanista respecto de la posibilidad de discutir si acaso un antecedente fundamental de la perspectiva transhumana se encuentre ya en el pensamiento de Friedrich Nietzsche.

El filosofo alemán contemporáneo Stefan Sorgner ha destacado la existencia de lo que a su juicio serían las importantes semejanzas que habría entre el concepto nietzscheano del "Superhombre" (Übermensch) y la idea del "posthumano" de Nick Bostrom (Sorgner 2009, p. 29), aunque más precisamente dicho las similaridades se darían con las ideas de otro filósofo exponente de esta misma teoría, que es Fereidoun M. Esfandiary, más conocido como FM-2030, un singular personaje de esta historia que tras su muerte acontecida en el año 2000 fue crionizado. Sorgner discute cuánto se asemejan ambos términos (Overhuman y Posthuman) en relación con la idea de que la humanidad es meramente un trabajo en progreso, con posibilidades futuras muy limitadas, de no introducírsele transformaciones radicales.

En otras palabras, como se ha señalado en líneas anteriores, Sorgner afirma que la humanidad no sería una culminación evolutiva, sino algo que clama por su mejoramiento. "Un ser humano en cuanto tal -nos dice Sorgner- tiene solo una cantidad limitada de potencial y capacidades, por pertenecer a la especie humana y debido a que cada especie está definida por sus límites. No puede ir más allá de ellos. Si un ser humano ha adquirido capacidades especiales, no puede transmitírselas a sus descendientes" (Ibíd.); no obstante, dado que Nietzsche ve a los filósofos como "creadores de valores", Sorgner entiende que ellos gobernarán a los siglos siguientes. Y supone que aunque nunca Nietzsche hubiera pensado que el advenimiento del Superhombre estuviera ligado a las transformaciones tecnológicas, ello era algo que el filósofo tampoco habría dejado de considerar, aunque fuera implícitamente. Sobre todo, si se tiene en cuenta que, en obras como Más allá del Bien y del Mal, por ejemplo, distinguió entre un espíritu científico y un espíritu religioso, caracterizando a este ultimo como el de aquellos seres humanos débiles, incapaces de cumplir sus aspiraciones en el aquí y el ahora, transfiriéndolas a un trasmundo, mientras describió, en cambio, a los seres humanos superiores y dominantes, haciéndose más fuertes y desarrollando un espíritu científico (Ibíd.).

Al mismo tiempo, Sorgner señala que aunque Nietzsche rechaza cualquier concepto trascendente, de todos modos encuentra valor en el interés de los "humanos superiores" por "superarse" a sí mismos de manera constante y permanente. El éxito del proyecto de creación de este "Superhombre" queda así atado al hecho de dar sentido a los seres humanos que están involucrados en el esfuerzo por la autosuperación. Para los individuos que tienen una visión materialista del mundo -que Sorgner la entiende 
como el "espíritu científico"- y que han rechazado la autoridad moral y epistemológica reclamada por el cristianismo, esto supone una nueva fuente de sentido. Sorgner destaca, en relación con ello, la alta impronta de estimaciones que subyace al proyecto del Superhombre nietzscheano y que conteniendo la importante dimensión valorativa que se le puede advertir en un texto como La Genealogía de la Moral, hace palidecer al débil soporte axiológico en que, a su juicio, se afinca el proyecto transhumanista, que no explica por qué o en qué sostiene los valores que dice sostener, ni tampoco da cuenta suficientemente de por qué ellos podrían llevar al ser humano hacia una condición de posthumanidad (Ibíd., p. 34).

Parece importante desviarse de los planteamientos de Sorgner en este instante, y retomar el texto Reglas para el Parque Humano de Sloterdijk -como se ofreció en las líneas iniciales- para considerar algunas afirmaciones que él hace sobre Nietzsche; en particular, aquellas que nos recuerdan las sospechas que el filósofo de Sils-Maria levantara contra toda cultura humanística, que permiten "revelar el secreto de la domesticación de la humanidad" (Sloterdijk 1999) y denunciar a quienes han detentado el monopolio de esa domesticación -el sacerdote y el maestro- "que se presentan a sí mismos como amigos del hombre" (Ibíd.). Sloterdijk señala la voluntad de Nietzsche -expresada en su obra Así habló Zarathustra-de desencadenar una nueva lucha de la historia mundial, aquella que se daría entre diversos programas de crianza y diversos criadores; la lucha entre los pequeños criadores y los grandes criadores de la humanidad; la lucha entre los humanistas y los superhumanistas, o los "transhumanistas" como también podríamos decir si siguiéramos la sintonía que Sorgner ha querido establecer entre el proyecto decimonónico nietzscheano y el actual proyecto posthumanista de mejoramiento humano propiciado por los desarrollos de la ciencia y de la técnica. En cualquier caso -sostiene Sloterdijk-, cuando Nietzsche habla de Übermensch, lo hace para referirse "a una época muy por encima del presente" y para connotar una historia milenaria en la que la conjunción de crianza, domesticación y educación dio con la producción de seres humanos, de un modo que supo hacerse invisible y que ocultó el proyecto de dominación que se traía entre manos en tanto se ocultaba bajo la máscara de la educación y el mejoramiento del hombre (Ibíd.).

\section{Transhumanismo y biopolítica}

En consecuencia, me parece enteramente lícito volver a levantar una sospecha en torno de estas cuestiones. Esta vez respecto de una eventual reedición del programa de crianza característicamente humanista, como el que pudiera estar produciéndose en nuestro tiempo, representado ahora por el programa transhumanista de pensamiento, que auspicia de manera irrestricta la idea de un mejoramiento humano, con recurso a las implementaciones tecnológicas actualmente disponibles y a aquellas otras que ciertamente lo estarán, tanto en el futuro inmediato como en el mediato.

Tal sospecha se fundaría en la advertencia de ciertos riesgos inherentes, sobre todo, a las definiciones políticas que cabría adjudicarle al proyecto transhumanista; 
más allá de la querella por la lesión virtual de la dignidad humana que la resistencia bioconservacionista ya le ha planteado (piénsese, por ejemplo, en la defensa de una "ética de la especie" por la que ha abogado Habermas); y más allá también del emplazamiento que las precauciones y restricciones normativas planteadas por la reflexión bioética le conminan a encarar hoy; que es una cuestión de la cual filósofos transhumanistas como Julian Savulescu no parecen haberse desentendido del todo, según lo testimonian algunas declaraciones suyas como las siguientes: "Necesitaremos una ética bien desarrollada para gobernar la creación de nuevas formas de vida [...] Una de las tareas más urgentes de la bioética moderna es elaborar y desarrollar un complejo marco normativo para evaluar la creación de animales [humanos y no humanos, habría que agregar] radicalmente modificados a nivel genético. La ciencia progresa exponencialmente, pero este asunto vital solo ha sido sometido hasta la fecha a un insuficiente escrutinio ético" (Savulescu 2012, pp. 338-340).

Los riesgos a los que aquí quiero aludir refieren principalmente a la connivencia no declarada y al ajustamiento interesado en que probablemente el proyecto transhumanista estuviera incurriendo con respecto a los fines de las sociedades occidentales, de disciplinamiento primero y de control luego, según han sido denominadas por autores como Michel Foucault (1975) o Gilles Deleuze (1999), respectivamente, y también por algunos de sus más directos seguidores contemporáneos (Esposito, Agamben, Rose, Miller, Fassin, Lazzarato y otros). En tal sentido, argumentaciones provenientes de la matriz de análisis de la biopolítica permitirían sospechar que el transhumanismo podría constituir una reiteración -claro que perfeccionada, sofisticada, consumada- de las formas históricas a través de las cuales el biopoder se ha instalado en Occidente moderno y ha devenido en un conjunto de prácticas de gobierno de los sujetos. Parte de los riesgos correspondería a la consolidación de una nueva escena de producción de las subjetividades -nuevas modalidades de crianza diría Nietzsche-, amparadas ahora en el saber biotecnológico e informático en curso de irrefrenable expansión. Dicho saber opera, como sabemos, definido por un ethos profundamente individualista; está enteramente determinado en cuanto a sus fundamentos por las leyes del mercado y su desarrollo solo es susceptible de producirse en un contexto de economía neoliberal globalizada.

No parece irrelevante tener en cuenta en este punto, como lo ha hecho por ejemplo un autor contemporáneo como Didier Fassin, que durante mucho tiempo el cuerpo constituyó un punto ciego para la investigación social y política (Fassin 2005). Aunque en las últimas décadas, y sobre todo a partir de los trabajos de Michel Foucault, la tematización del asunto del cuerpo -entendido como el horizonte de despliegue de lo social y lo político- constituye hoy un pie forzado de la discusión. No obstante -cree Fassin-, aunque fecunda, esta apertura no habría abordado suficientemente un asunto capital como el de "los usos políticos del cuerpo" (Ibíd.). Ello se torna muy relevante para esta reflexión, sobre todo si se considera que en relación con el tema del transhumanismo, literalmente ese poder se manifiesta en la carne del individuo, a tal punto que no resultaría errado hablar de un verdadero fenómeno de in-corporación del poder. En tal sentido, como señala Fassin, en la época presente "el orden del mundo se inscribe en el cuerpo" (Ibíd.). En un sentido muy semejante, otro autor contemporáneo, 
el británico Nikolas Rose, también ha buscado entender y establecer el papel que las ciencias han jugado en la vinculación de la vida subjetiva e intersubjetiva con los sistemas de poder político (Rose 1990).

Según dicho esquema de análisis biopolítico de evolución de la sociedad contemporánea y la determinación de su ingreso en la lógica de administración de la vida desde las referencias políticas, se puede presumir que el transhumanismo no representa sino la fase superior de aherrojamiento de la vida. En este sentido, históricamente ha sido la biomedicina la que ha operado como el saber de base que, pretendiendo resolver los problemas sanitarios de la sociedad tradicional, ha ofrecido "mejorar" la existencia de los individuos y las poblaciones, estableciendo ese inédito régimen de dominación en el que a la vida se le hizo ingresar en los cálculos explícitos del poder.

Someter, entonces, al proyecto transhumanista a un escrutinio respecto de sus implicancias biopolíticas y no abordarlo únicamente desde la precaución bioética fundada en el reconocimiento o el desconocimiento de la dignidad -que es cuanto hasta ahora más ha ocurrido-, parece una opción completamente decisiva para la reflexión contemporánea; más aún, en tanto el transhumanismo podría representar una extensión inadvertida del poder sobre la vida, ya que está desplegado a partir de referencias persuasivas que impiden detectar los riesgos de control que implica. Se requiere, por tanto, una indagación que busque advertir sus verdaderas implicancias de intervención política sobre la vida humana, en cuanto por esa vía puede llegar a favorecer la perpetuidad de los sistemas de poder establecidos.

Atendida la prevención señalada, no parecería poco razonable suponer que este poder se pudiera ver acrecentado en la medida en que opere sobre nuevas escenas de la vida humana que remitirán a una administración planificada de la constitución micromolecular de los sujetos o al incremento de sus capacidades. En escritos anteriores ya he reflexionado sobre el asunto de la administración biopolítica de la intimidad en los biobancos, como ejemplo del riesgo en que las biotecnologías pueden hacer entrar a la subjetividad en el presente (Villarroel 2013). Ello podría ir todavía un poco más lejos, si se omite toda referencia a las previsibles consecuencias de manejo interesado de tales capacidades y mejoras por parte de los sistemas de poder, que verían la oportunidad de potenciar sus intereses a partir de estos nuevos sujetos, ahora incluso más susceptibles de dominación. El mejoramiento produciría individuos mucho más aptos (mejorados) que aquellos otros individuos históricos "normales" y precarios en cuanto a sus capacidades (obreros, estudiantes, presidiarios, artesanos, funcionarios, etc.) sobre los que recayó hasta hace algunas décadas la disciplina-según el relato foucaultiano-para conseguir ahora en mayor medida los objetivos logrados hasta hoy en escala menor. Las preguntas del presente en relación con el programa transhumanista de mejoramiento humano parecen ser inevitablemente entonces: ¿mejorar a quién?, ¿mejorar qué? (Koch 2010), ¿mejorar para qué? O bien, ¿qué derechos sociales, políticos, laborales, asistirán a estos nuevos sujetos y garantizarán su plena participación ciudadana y una distribución equitativa de las cargas y los beneficios sociales que los definirán? Cuestiones como estas parecen inevitables a la hora de evaluar la viabilidad de un proyecto de transformación humana como el que aquí analizamos. 
Y es que también se puede establecer la misma saludable prevención respecto de la posibilidad de que el mejoramiento anunciado termine implementándose solo en función de la ampliación de las capacidades de los sujetos pertenecientes al segmento social hoy dominante en el planeta, que cuenta con abundantes medios económicos como para adquirir esas nuevas herramientas de ampliación de sus capacidades y de la duración de sus vidas que ofrecerá el mercado, teniendo en cuenta que los desarrollos biotecnológicos operan en el contexto del actual modelo económico y al interior de los inequitativos sistemas privados de salud como los que hoy caracterizan a las sociedades occidentales. Parece posible pensar que de tal manera lo que ocurriría no sería otra cosa que una consolidación cada vez mayor de la actual supremacía ejercida por los grupos que detentan el poder político y acumulan la riqueza en el mundo. El contexto del transhumanismo y de las transformaciones propiciadas por la implementación creciente de sistemas biotecnológicos e informáticos es necesariamente el de la economía neoliberal prevaleciente y por lo tanto está inevitablemente determinado en cuanto a su desarrollo por las leyes que rigen la expansión del sistema económico.

Entender los riesgos, por tanto, equivale a poner atención al posible proceso de sometimiento al que sus vidas llegarán a ser expuestas, más que solo a las expectativas de beneficio y mejora que supuestamente trae consigo la oferta transhumanista. Porque lo que la política es capaz de hacer con la vida de las personas no remite únicamente a un asunto de discursos biomédicos o de tecnologías (Fassin 2005). Tiene que ver con el modo real en que los grupos e individuos ampliados en sus capacidades serán tratados; según qué rendimientos se les exigirá responder socialmente; mediante qué criterios se evaluarán sus mejoradas vidas futuras, conforme a qué tipo de desigualdades y en ausencia de qué reconocimientos se les excluirá (Ibíd.).

Ya para terminar, quisiera compartir, a modo de resumen del propósito perseguido por esta reflexión, unas interesantísimas consideraciones del filósofo italiano Roberto Esposito, quien mediante su noción de una "biopolítica afirmativa" busca revertir la comprensión histórica del fenómeno de la dominación -según la había dejado establecida Foucault-, para intentar establecer una relación de naturaleza productiva entre el poder y los sujetos; que, en lugar de someter y objetivar a la subjetividad, propicie su expansión y su potenciación. Que es lo que constituiría, a nuestro juicio, la veladura del transhumanismo, el borde desconocido de realidad del que no parece haberse hecho cargo hasta ahora; permitiendo, en cambio, albergar un sinnúmero de sospechas respecto de sus previsibles proyecciones en tanto pudiera constituir la nueva fórmula enmascarada del poder. Esposito ha señalado: "Se podría, en fin, hablar de política de la vida y no sobre la vida. No solo si la vida, cada vida individual, es sujeto y no objeto de la política, sino también si la misma política es repensada mediante un concepto de vida de acuerdo con toda su extraordinaria complejidad interna, sin reducirla a la simple materia biológica" (Castro 2005).

La dinámica de este debate es tan vertiginosa que no permite cerrar la discusión simplemente adhiriendo a una u otra perspectiva de las que aquí han sido presentadas. El devenir de lo humano seguirá siendo un asunto de profundas discrepancias éticas, sin duda alguna. No obstante, sin haber pretendido declarar estéril la confrontación teórica entre transhumanistas y bioconservacionistas que he descrito en las páginas precedentes, 
sí me ha parecido prudente imprimirle un sutil desplazamiento teórico al conjunto de la argumentación presentada. El propósito perseguido en este sentido tiene que ver con la posibilidad de redirigirla hacia otro tipo de consideraciones filosóficas. Estas provienen de la matriz de análisis de la biopolítica, que define de manera irrenunciable el horizonte de la reflexión actual, teniendo a la vista un compromiso ineludible con la deriva crítica del pensamiento.

Ello implica, a mi juicio, cuestionar la conurbación a veces desmedida que el saber científico tiende a establecer respecto de nuestras actuales visiones de mundo y abrir espacios para una evaluación verdaderamente responsable de nuestro futuro común, que es lo que aquí hemos buscado hacer.

\section{Referencias bibliográficas}

Annas, G.; Andrews, L, y R. Isasi (2002), "Protecting the endangered human: toward an international treaty prohibiting cloning and inheritable alterations", American Journal of Law Medicine 28 (2-3): 151-78. Traducción propia.

Beck, U. (1998), La sociedad del riesgo. Hacia una nueva modernidad. Barcelona: Paidós.

Blackford, R. (2004), Humanity enhanced. Genetic choice and the challenge for liberal democracies (Basic bioethics). Massachusetts: MIT Press.

Bostrom, N. (2005a), "A history of transhumanist thought", Journal of Evolution \& Technology 14: (1).

3.

(2005b), "In defense of posthuman dignity", Bioethics, vol. 19, number

Castro, E. (2005), "Toda filosofía en sí es política. Entrevista a Roberto Esposito". Revista N, Diario Clarín, Buenos Aires, edición del 12 de marzo de 2005.

Deleuze, G. (1999), "Post-scriptum a la sociedades de control" en Deleuze, G., Conversaciones. Valencia: Pre-textos.

Fassin, D. (2005), "Gobernar por los cuerpos. Políticas de reconocimiento hacia los pobres y los inmigrantes", Revista Educaçao, año $28 \mathrm{~N}^{\circ} 2$ (56): pp. 201-226.

Foucault, M. (1975), Vigilar y castigar. Madrid: Alianza.

Fukuyama, F. (2002), Our posthuman future. Consequences of the biotechnology revolution. Oxford: Oxford University Press. Traducción propia.

(2004), "Transhumanism". Foreign Policy, oct-nov.

Habermas, J. (2001), El futuro de la naturaleza humana. ¿Hacia una eugenesia liberal? Buenos Aires: Paidós.

Jonas, H. (1995), El principio de responsabilidad. Ensayo de una ética para la civilización tecnológica. Barcelona: Herder.

Kass. L. (2003), "Ageless Bodies, Happy Souls: Biotechnology and the Pursuit of Perfection”. The New Atlantis. Spring (1): 9-28. Traducción propia. 
Koch, T. (2010), "Enhancing who? Enhancing what? Ethics, Bioethics and Transhumanism”, Journal of medicine and Philosophy 35: 685-699.

Garrido, M. (2007), “La explosión de la tecnología: tres metáforas para el siglo XXI”, en Garrido, M.; L. M. Valdés y L. Arenas, coords. El legado filosófico y científico del siglo $X X$. Madrid: Cátedra, cap. 35, pp. 867-886.

More, M. and N. Vita-More (eds.) (2013), The transhumanist reader. Classical and contemporary essays on the science, technology, and philosophy of the human future. West Sussex: Wiley Blackwell.

Rose, N. (1990), Governing the soul. The shaping of the private self. New York: Routledge.

Savulescu, J. (2012), ¿Decisiones peligrosas? Una bioética desafiante. Madrid: Tecnos.

Savulescu, J. and N. Bostrom (eds.). (2003), Human enhancement. Oxford: Oxford University Press.

Sloterdijk, P. (1999), "Reglas para el parque humano. Una respuesta a la Carta sobre el Humanismo". Conferencia pronunciada en el castillo de Elmau, Baviera, julio de 1999. Tomada de http://www.heideggeriana.com.ar/comentarios/sloterdijk. $\operatorname{htm}(30.10 .14)$

Sorgner, S. (2009), "Nietzsche, the Overhuman and Transhumanism", Journal of Evolution and Technology, Vol. 20, Issue 1, March, pp. 29-42.

Sorgner, S. and B. Jovanovic (eds.). (2013), Evolution and the future. Anthropology, Ethics, Religion. Pieterlen: Peter Lang edition.

Villarroel, R. (2013), “Administración biopolítica de la intimidad en los Biobancos”, Acta Bioethica, junio, vol. 19, No 1: pp. 39-47. 